\title{
Serious Liver Trauma: Predictive Factors Of Therapeutic Choice And Prognostic Factors (About 65 Cases)
}

\author{
K. Elhattabi, A. Bachar, F. Z. Bensardi, K. Mourid and A. Fadil
}

\begin{abstract}
The charge of the severe hepatic traumas underwent a radical change from exclusive surgical treatment to non-operative-based conservative approach that benefited from the recent advances in the field of imagery as well as from the follow-up strategies of intensive care.

A retrospective survey was carried out involving 65 patients treated for serious liver traumas in the surgical emergency department of Ibn Rochd university hospital of Casablanca.

The aim of this study is to assess our act refunding SLT through the definition of the evolutionary, therapeutic, diagnostic, and epidemiological data.

All the penetrating and blunt SLT were included in this survey. The seriousness was defined by the hemodynamic instability and a lesion stage higher to III according to the MIRVIS rating. The clinical and paraclinical data as well as morbidity and mortality were analyzed.

Traffic accidents were the main cause of SLT our series is mainly composed of young male subjects ( 54 men, $83 \%$ ). There were $86 \%$ of blunt traumas (56 cases) there was common polytrauma $(\mathbf{7 8 , 5 \%})$. Ultrasound and CT scans were performed to most patients (respectively $83 \%$ and $78 \%$ ). Fifty one patients had non operative treatment $(78,5 \%)$ whereas 14 patients underwent surgery. This option was due to their hemodynamic instability and not the hepatic trauma lesion stage in the operative group, the evolution was complicate in $35,7 \%$ of the operated patients whereas in the non operative group the complications supervened only in $23,5 \%$ of the cases. The mortality rate was respectively $28,5 \%$ versus $7,8 \%$ for the non operative treatment the NOT of the SLT allowed to obtain satisfactory results despite the seriousness of the hepatic lesions.

It should be anted that the treatment choice was made mainly according to the hemodynamic condition and not to the radiological stage lesions

A genuine and precocious agreement among the surgeon, the anesthesiologist and the interventional radiologist allowed to avoid the server complications following SLT so that the injured patient who could be initially rescued manage to escape first hour complications, and ultimately recover.
\end{abstract}

Index Terms - Liver; Blunt injury; Non operative Management; prognostic; Delayed surgery.

\section{INTRODUCTION}

Serious liver traumas are diagnostic and therapeutic emergency requiring a multi-disciplinary take-in-charge. They correspond to any hepatic trauma with or without parietal continuity solution, whose MIRVIS - CT ranking is

Published on June 2, 2020.

K. Elhattabi, Visceral Surgery Emergency Department, University Hospital Ibn Rochd Casablanca, Morocco.

A. Bachar, Visceral Surgery Emergency Department, University Hospital Ibn Rochd Casablanca, Morocco.

(corresponding e-mail: bachar.amine81@gmail.com) higher than III stage and/or combined to hemodynamic unsteadiness [1]. Serious liver trauma prevalence varies between $11,4 \%$ and $49 \%$ of all the hepatic traumas according to the series $[2,3,4,5,6]$. They are either due to penetrating traumas during road accidents or due to blunt traumas during aggressions with weapons. For years the operative treatment was considered the only therapeutic means in case of serious hepatic trauma. However, this attitude has progressively been turned into a more conservative approach thus avoiding urgent operating of the injured whenever possible. This dogma was also shaken by the concept of shortened laparotomy (damage control) in the form of a perihepatic compression of the liver. It is a process that has genuinely altered the management of SLT for which an emergency intervention was required before [7]. The presence of active arterial extravasation on the scanner with injected sequences accounts for hemostasis surgery. However, since the supervention of hepatic arterial embolization techniques (HAE) percutaneously, surgery is no more sought as the first intent. Nowadays, a better understanding of the symptomatology of the large uncontrolled haemorrhagies, the development of the arteriography, the embolization and the resuscitation (or intensive care) have allowed to opt for a conservative treatment in $80 \%$ of the cases of SLT [8] with an improvement of mortality rate that decreases from $28 \%$ to $7,9 \%[8,9]$.

The aim of our study is to define the predictive factors of the therapeutic choice between a surgical and conservative treatment and the prognostic factors through a retrospective, analytic and descriptive study.

\section{MATERIAL AND METHODS}

Our retrospective survey involves patients having serious liver trauma admitted to the visceral emergency department (P35) of Ibn Rochd University Hospital of CASABLANCA over a period of 3 years that lies from January 2013 through $17^{\text {th }}$ April 2016. In accordance with literature, the seriousness of the hepatic lesion was defined according to MIRVIS-CT rating. Only the patients having stage III hepatic lesion or more, with or without hemodynamic instability, were included. The patients who passed away or those with extrahepatic hemodynamic instability were excluded.

A unvaried and multivaried analysis using SPSS 23.0

F. Z. Bensardi, Visceral Surgery Emergency Department, University Hospital Ibn Rochd Casablanca, Morocco.

K. Mourid, Visceral Surgery Emergency Department, University Hospital Ibn Rochd Casablanca, Morocco.

A. Fadil, Visceral Surgery Emergency Department, University Hospital Ibn Rochd Casablanca, Morocco. 
version software was carried out in order to identify the predictive factors of the therapeutic choice as well as the prognostic factors, the results maintained as significant were those with $\mathrm{P} \leq 0.05$.

\begin{tabular}{cl}
\multicolumn{2}{c}{ TABLE I: MIRVIS-CT RATING } \\
\hline \hline Grade & \multicolumn{1}{c}{ Criteria } \\
\hline I & $\begin{array}{l}\text { Capsular avulsion, superficial fractures }<1 \mathrm{~cm} \text { in depth, sub- } \\
\text { capsular hematomas }<1 \mathrm{~cm} \text { maximal thickness, periportal } \\
\text { infiltration. }\end{array}$ \\
\hline II & $\begin{array}{l}\text { Fractures of } 1 \text { to } 3 \mathrm{~cm} \text { in depth, central or sub-capsular } \\
\text { hematoma of } 1 \text { to } 3 \mathrm{~cm} \text { in diameter. }\end{array}$ \\
\hline III & $\begin{array}{l}\text { Fracture(s) of }>3 \mathrm{~cm} \text { in depth, central or sub-capsular } \\
\text { hematoma of }>3 \mathrm{~cm} .\end{array}$ \\
\hline IV & $\begin{array}{l}\text { Central or sub-capsular massive hematoma of }>10 \mathrm{~cm}, \text { lobar } \\
\text { tissular destruction or devascularization. }\end{array}$ \\
\hline V & Bilobar tissular destruction o devascularization. \\
\hline \hline
\end{tabular}

\section{RESULTS}

During the same period, 255 patients were hospitalized for abdominal contusion. $25,4 \%$ showed S L T of which $83 \%$, were penetrating traumas. The mean age was 32 years with an age interval of 15 to 60 years of which males represent $83,1 \%$. Road accidents were the most frequent cause $(63,1 \%)$. A quarter of the patients showed hemodynamic instability at admission. The RTS score was 7,07 in average. The right hypochondrium pain was predominant in the clinical symptomatology.

Hemoglobin was $\leq 9 \mathrm{~g} / \mathrm{dL}$ in $34 \%$ of the patients and $94 \%$ showed hepatic cytolysis. Half of our patients underwent abdominal echography showing a peritoneal outpouring and in $51 \%$ of the cases, there was a case of hepatic contusion.

Practically all our patients underwent TDM revealing hepatic confusions in 52 patients hepatic fractures in 10 patients and subcapsular hematoma in III patients among whom one patient had the 3 lesions at the same time. These hepatic lesions were MIRVIS stage III in 78,1\%. Twenty percent of the patients had stage IV and stage $\mathrm{V}$ was detected only in one case. Intensive care measures were taken of all patients. The onset laparotomy was advised in $22 \%$ of the patients whose hemodynamic instability was not rectified by intensive care measures was the cause for 11 patients and the suspicion of the perforation of the digestive tube in 3 patients. The liver had already made its hemostasis in $57 \%$ of the patients and in $43 \%$ it required a peri-hepatic compression which was a suture. There was a wound of the lower vena cava in 1 patient.

The average stay in hospital was 12 days. The evolution was favorable in 5 patients. The rest of the patients showed complications. Mortality rate was $28,5 \%$ in the operative treatment group. During our survey $78 \%$ of the patients underwent a non operative treatment based on a strict surveillance in surgical milieu outside the hemodynamic instability or acute abdomen signs. The duration of the hospital stay was 7 days in average. The evolution was favorable for $76,5 \%$ of the cases whereas $23,5 \%$ of the cases had complications among whom 11 patients had secondary surgery for extra-hepatic cause for most of these patients. The mortality rate was $7 \%$ in this group.

The analytic survey of the quality and quantity variables allowed us to detect the predictive factors of the therapeutic choice between a OT and a NOT and the prognostic factors showed in the tables 2 and 3 .

TABLE II: PREDICTIVE CHART OF MORTALITY

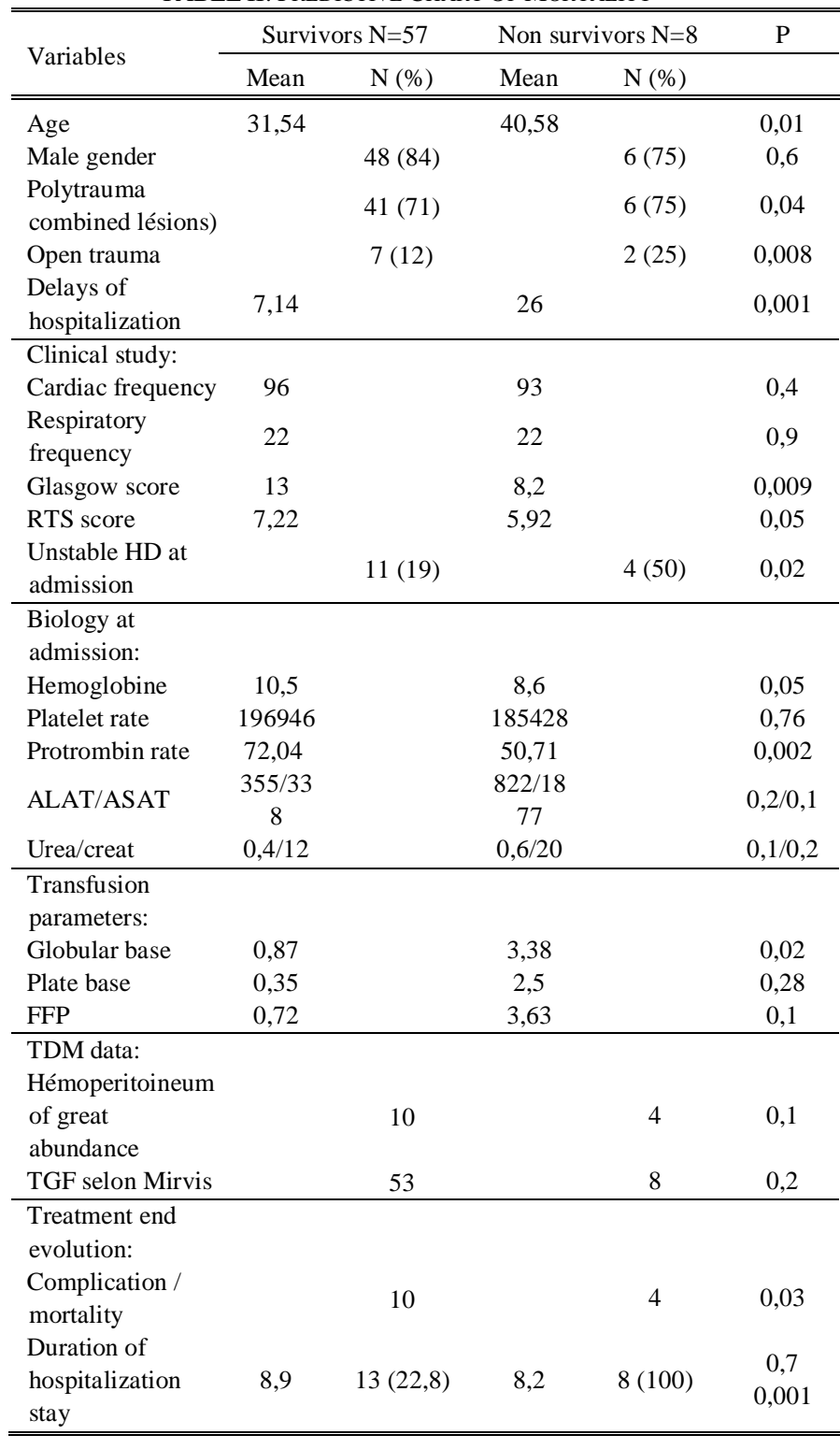

\section{CONClusion}

SLT mainly affects the young adult most frequently during road accidents. It is rarely isolated and often integrated in a poly-trauma context. The hemorrhagic shock remains the first decisive element in the take-in-charge of the SLT. The setting of the non operative treatment and its consideration as a firstchoice treatment for the hepatic lesions, with a success rate reaching $95 \%$, It eventually concerns more than $80 \%$ of the serious traumas of the liver (SLT).

The non operative take-in-charge is characterized by the existence of a very effective therapeutic trio: Radiology with injected TDM and hepatic arterial embolization, careful armed surveillance and finally the deferred operation. The latter is not to be considered as a failure of the take-in-charge by the non operative treatment. On the contrary, it is an integrated part of the therapeutic strategy. 
TABLE III: OPERATIVE TREATMENT END NON OPERATIVE TREATMENT

\begin{tabular}{|c|c|c|c|c|c|}
\hline \multirow[t]{2}{*}{ Variables } & \multicolumn{2}{|c|}{$\begin{array}{l}\text { Non operative } \\
\text { treatment } N=51\end{array}$} & \multicolumn{2}{|c|}{$\begin{array}{c}\text { Operative } \\
\text { treatment } \mathrm{N}=14\end{array}$} & \multirow[t]{2}{*}{$P$} \\
\hline & Mean & $\mathrm{N}(\%)$ & Mean & $\mathrm{N}(\%)$ & \\
\hline Age & 31,63 & & 36,29 & & 0,18 \\
\hline Male gender & & $\begin{array}{c}44 \\
(86,27)\end{array}$ & & $\begin{array}{c}10 \\
(71,42)\end{array}$ & 0,18 \\
\hline $\begin{array}{l}\text { Polytrauma } \\
\text { combined } \\
\text { lésions) }\end{array}$ & & $36(70,5)$ & & $11(78,5)$ & 0,39 \\
\hline $\begin{array}{l}\text { Delays of } \\
\text { hospitalization }\end{array}$ & 6 & & 5,2 & & 0,06 \\
\hline Open trauma & & $4(7,84)$ & & $5(35,71)$ & 0,007 \\
\hline Clinical study: & & & & & \\
\hline Cardiac frequency & 95 & & 98 & & 0,5 \\
\hline $\begin{array}{l}\text { Respiratory } \\
\text { frequency }\end{array}$ & 22 & & 25 & & 0,2 \\
\hline Glasgow score & 13 & & 11 & & 0,09 \\
\hline RTS score & 7,34 & & 6,05 & & 0,003 \\
\hline $\begin{array}{l}\text { Unstable } \\
\text { hemodynamic } \\
\text { condition at } \\
\text { admission }\end{array}$ & & $5(9,80)$ & & $\begin{array}{c}11 \\
(78,57)\end{array}$ & 0,001 \\
\hline $\begin{array}{l}\text { Biology at } \\
\text { admission: }\end{array}$ & & & & & \\
\hline Hemoglobine & 10,7 & & 8,4 & & 0,002 \\
\hline Plateles rate & 204313,7 & & 158916,6 & & 0,13 \\
\hline Protrombin rate & 71,9 & & 60,1 & & 0,039 \\
\hline ALAT/ASAT & $352,8 / 327,2$ & & $\begin{array}{c}637,4 / 12 \\
82,7\end{array}$ & & $0,05 / 0,1$ \\
\hline Urea/creat & $0,4 / 12,49$ & & $0,47 / 16,5$ & & $0,58 / 0,21$ \\
\hline $\begin{array}{l}\text { Transfusion } \\
\text { parameters: }\end{array}$ & & & & & \\
\hline Globular base & 0,71 & & 2,86 & & 0,003 \\
\hline Plate base & 0,18 & & 2,21 & & 0,001 \\
\hline FFP & 0,53 & & 3,07 & & 0,008 \\
\hline $\begin{array}{l}\text { TDM data: } \\
\text { Hémoperitoineum } \\
\text { of great } \\
\text { abundance }\end{array}$ & & $10(19,6)$ & & $7(50 \%)$ & 0,001 \\
\hline $\begin{array}{l}\text { Treatment end } \\
\text { evolution: }\end{array}$ & & & & & \\
\hline Complication & & $12(23,5)$ & & $9(64,3)$ & 0,04 \\
\hline Mortality & & $4(7,8)$ & & $4(28,5)$ & 0,03 \\
\hline $\begin{array}{l}\text { Duration of } \\
\text { hospitalization } \\
\text { stay }\end{array}$ & 7,96 & & 12 & $8(100)$ & 0,009 \\
\hline
\end{tabular}

\section{REFERENCES}

[1] F. R. Pruvot, F. Meaux, S. Struant, I. Plénier, A. Sourdement, L. Gaubiez, J. P. Triboulet et al., "Severe blunt liver injury: reappraisal of criteria for nonoperative management decision. Experience with 88 cases", Annales of surgy, vol. 130, pp. 70-80, 2005

[2] N. Cheynel, "Hepatic trauma. Epidemiology of road accidents o en physiopathology: biomécanic studys”, Life Sciences. Bourgogne university, 2007.

[3] S. Di Saverio et al., "Predictive factors of morbidity and mortality in grade IV and V liver trauma undergoing perihepatic packing: single institution 14 years experience at European trauma centre", Injury, vol. 43 (9), pp. 1347-1354, 2012

[4] Th. M. Zago et al., "Blunt hepatic trauma: comparison between surgical and nonoperative treatment", Revista do Colégio Brasileiro de Cirurgiões, vol. 39 (4), pp. 307-313, 2012.

[5] G. M. van der Wilden et al., "Successful nonoperative management of the most severe blunt liver injuries: a multicenter study of the research consortium of new England centers for trauma", Archives of Surgery, vol. 147 (5), pp. 423-428, 2012.

[6] W. H, She, T. T. Cheung, W. C. Dai, S. H. Y. Tsang, A. C. Y. Chan, D. K. H. Tong, G. K. K. Leung, and C. M. Lo, "Outcome analysis of management of liver trauma: A 10 -year experience at a trauma center", World Journal of Hepatology, vol. 8(15), pp. 644-648, 2016.
[7] M. Hommes et al., "Management of blunt liver trauma in 134 severely injured patients", Injury, vol. 46 (5), pp. 837-842, 2015.

[8] C. Letoublon et al., "Management of blunt hepatic trauma", Journal of Visceral Surgery, vol. 153 (4), pp. 33-43, 2016.

[9] A-F.S. Truant Bouras, and F-R. Pruvot, "Taking-in-care of serious hepatic trauma", Journal de Chirurgie Viscérale, vol. 147 (6), pp. 440447, 2010

[10] A. Ait Ali et al., "Interest the non operative treatment in hepatic lesions", Africain Hepato-gastroentérology journal, vol. 3 (2), pp. 81 $87,2009$.

[11] L. Romano, S. Giovine, G. Guidi, G. Tortora, T. Cinque, and S. Romano, "Hepatic trauma: CT findings and considerations based on our experience in emergency diagnostic imaging", European Journal of Radiology, vol. 50 (1), pp. 5059-66, 2004

[12] Ministry of health, Morocco kingdom. Health in numbers 2014, édition 2015.

[13] D. Sahani, A. Mehta, M. Blake, et al., "Preoperative Hepatic Vascular Evaluation with CT and MR Angiography: Implications for Surgery", Radio Graphics, vol. 24, pp. 1367-1380, 2004.

[14] Shawn D. St. Peter, P, Aguayo, D. Juang, and S. W. Sharp, "Follow up of prospective validation of an abbreviated bedrest protocol in the management of blunt spleen and liver injury", Journal of Pediatric Surgery Pubmed, vol. 48 (12), pp. 24372441, 2013.

[15] C. Topping, "FAST écho", Le Médecin du Québec, vol. 40(8), pp. 614, 2005.

[16] F. Adnet, M. Galinski, F. Lapostolle, "Fast echography in the emergency setting", 2004.

[17] C. Ridereau-Zins et al. "Traumatismes abdominaux: les lésions élémentaires", Journal de Radiologie, vol. 89 (11), pp. 1812-1832, 2008.

[18] W. Yoon, Y. Y. Jeong, J. Kyu Kim, "CT in Blunt Liver Trauma”, Radio Graphics, vol. 25, pp. 87-104, 2005.

[19] B. Vigué, K. Tazarourte, "Prédiction et mortalité annoncée en traumatology", 52e Congrès National d'Anesthésie et de Réanimation Médecins, Urgences Vitales, 2010.

[20] R. Rossaint, B. Bouillon, V. Cerny, T. J. Coats, J. Duranteau, E. Fernandez-Mondejar, et al. "Management of bleeding following major trauma: an updated European guideline.”, Critical Care, vol. 14, R52, 2010.

[21] J. Richardson, G. Franklin, J. Lukan, et al. "Evolution in themanagement of hepatic trauma: a 25-year perspective", Ann Surg, vol. 232, pp. 324- 330, 2000. 